\title{
Correspondence
}

\section{Dorsal column function after spinal/epidural anaesthesia}

I take issue with Parry et al.'s suggestion that walking 'remains a safe option in the majority of parturients after low-dose epidural and combined spinal/epidural (CSE) labour analgesia' (Anaesthesia 1998; 53: 382-7). In their study of dorsal column function in labouring patients receiving either intrathecal bupivacaine $2.5 \mathrm{mg} /$ fentanyl $25 \mu \mathrm{g}$ (in $1 \mathrm{ml}$ ), epidural bupivacaine $15 \mathrm{mg} / \mathrm{fen}-$ tanyl $30 \mu \mathrm{g}$ (in $15 \mathrm{ml}$ ) or dense spinal anaesthesia for Caesarean section (bupivacaine $10 \mathrm{mg} /$ fentanyl $25 \mu \mathrm{g}$ ), they found the incidence of dorsal column impairment merely 7\%, compared with up to $66 \%$ in our earlier work [1]. Their methodology does not justify this conclusion for the following reasons, although the unknown effect of prolonged or repeated doses of local anaesthetics on dorsal column sensation is acknowledged.

Firstly, assessment of proprioreception began 20-30 min following instigation of analgesia, in contrast to our studies, which assessed dorsal column signs before, as well as after, onset of labour analgesia [1,2]. This had the effect of familiarising patients with the postintervention tests, rendering them more likely to be accurately reported and valid [3]. Furthermore, Parry et al. do not detail how they actually conducted their test of distal joint proprioreception, except to state there was 'manual displacement of the large toe and ankle joint'. We offered each patient a choice of three responses to distal interphalangeal movement, i.e. 'up', 'down' or 'don't' or 'don't know' and took six trials, both before and after the analgesic intervention [2]. Three or more incorrect responses from six attempts were required after the analgesia in our study before a patient was classified as having 'abnormal' proprioreception.

Similarly, the pilot study quoted as showing no dorsal column impairment after standard intrathecal analgesia does not report its methods in detail [4], which is crucial where there are no objective measures of impairment and signs may vary subjectively. Clinical studies in this area highlight the difficulty of objectively measuring neurological signs in general and dorsal column sensory modalities in particular. Somatosensory evoked potentials have been mooted as a putative objective means of dorsal column function assessment, but current evidence indicates that while it may be a useful barometer of global spinal cord function, dorsal column modalities cannot currently be distinguished from other modalities travelling in the spinocerebellar tracts, for example [5]. In these circumstances, it is important to minimise interobserver variability by having a single investigator perform all neurological assessments. While Parry et al. were unaware of the study group to which the patient they were examining belonged, it is unclear whether more than one co-author conducted these clinical evaluations.

While Parry et al. are to be commended on their ingenuity in designing a purpose-built $128-\mathrm{Hz}$ device for delivering a vibratory stimulus, such lengths were hardly necessary, given that the traditional clinical method of using the tuning fork is perfectly adequate to evaluate vibration sense if used correctly [3]. Moreover, they report testing the lateral malleolus and head of fibula, despite the teaching that this test ought to commence distally at the terminal interphalangeal joint of the great toe, where a vibration abnormality may be detected with greater sensitivity than at the more proximal sites [3]. Importantly, Parry et al. did not report any assessment of Romberg's sign, which is surprising in view of their emphasis on the concept that safe walking depends on maintenance of balance. A recent editorial suggested testing Romberg's sign would be a minimum test requirement before allowing ambulation [6]. I would also disagree with their interpretation of the effect of increasing dose of local anaesthetic on different types of nerve fibres. Scurlock et al. showed that sensitivity to local anaesthetics was dependent on the rate of basal discharge of nerve fibres and because proprioreceptive fibres have a greater rate of impulse transmission, they are more sensitive to a given dose of local anaesthetic than similarly sized motor fibres [7]. Finally, as the authors state, it is unlikely that compensatory adjustments in balance and posture could occur as rapidly as onset of dorsal column impairment after regional analgesia, especially since the physiological postural changes of pregnancy shift the normal centre of gravity of the woman's body anteriorly, rendering balance more difficult [8].

In summary, I welcome Parry et al.'s concluding call for dorsal column function to be assessed and found normal before permitting ambulation after

All correspondence should be addressed to Dr M. Morgan, Editor of Anaesthesia, Department of Anaesthetics, Royal Postgraduate Medical School, Hammersmith Hospital, London W12 OHS, UK.

Letters (two copies) must be typewritten on one side of the paper only and double spaced with wide margins. Copy should be prepared in the usual style and format of the Correspondence section. Authors must follow the advice about references and other matters contained in the Notice to Contributors to Anaesthesia printed at the back of each issue. The degree and diplomas of each author must be given in a covering letter personally signed by all the authors.

Correspondence presented in any other style or format may be the subject of considerable delay and may be returned to the author for revision. If the letter comments on a published article in Anaesthesia, please send three copies; otherwise two copies of your letter will suffice. 
regional analgesia for labour, as the safety of this practice has not been clearly established.

\section{Buggy \\ Leicester General Hospital, Leicester LES 4PW, UK}

\section{References}

1 Buggy DJ, Hughes N, Gardiner J. Posterior column sensory impairment during mobile extradural analgesia in labour. British Journal of Anaesthesia 1994; 73: 540-2.

2 Buggy DJ, MacDowell C. Extradural analgesia with clonidine and fentanyl compared with $0.25 \%$ bupivacaine in the first stage of labour. British Journal of Anaesthesia 1996; 76: 319-21.

3 MacLeod J (ed.). Clinical examination, 6th edn. Edinburgh: ChurchillLivingstone, 1983; 267-95.

4 Plaat F, Singh R, Alsoad SM, Crowhurst JA. Selective sensory blockade with low-dose combined spinal-epidural allows safe ambulation in labour: a pilot study. International Journal of Obstetric Anaesthesia 1996; 5: 220.

5 Loughnan BA, Fennelly ME, Henley M, Hall GM. The effects of differing concentrations of bupivacaine on the epidural somatosensory evoked potentials after posterior tibial nerve stimulation. Anesthesia and Analgesia 1995; 81: 147-51.

6 Elton CD, Ali P, Mushambi MC. Walking epidurals in labour: a step forward? British Journal of Anaesthesia 1997; 79: 551-4.

7 Scurlock JE, Meymaris E, Gregus J. The clinical character of local anaesthetics: a function of frequencydependent conduction block. Acta Anaesthesiologica Scandinavica 1978; 22: 601-8.

8 MacEvilly M, Buggy D. Back pain and pregnancy. Pain 1996; 64: 405-14.

\section{A reply}

Thank you for the opportunity to respond to Dr Buggy's letter commenting on our recent article (Anaesthesia 1998; 53: 382-7).

We disagree that our methodology is flawed. We considered it unethical to withhold epidural analgesia in labour until detailed dorsal column testing was performed as Dr Buggy did [1] in his highly criticised paper [2]. Although not stated in our article, distal joint proprioception was recorded in a similar way to that of Buggy et al. [1]. Plaat et al.'s study, reported in abstract form, found no evidence of dorsal column impairment in any of their patients, which is far more in keeping with our own data than that of Buggy et al. [1].

Using somatosensory evoked potentials (SEPs) to assess dorsal column function after low-dose combined spinalepidural (CSE) labour analgesia, we found no difference in $\mathrm{P} 40$ latencies compared to a control group [3]. Stimulation of the posterior tibial nerve at the ankle, as performed in this study, is known to evoke positive scalp potentials with initial latencies at $40 \mathrm{~ms}[\mathrm{P} 40]$ and compromise of this pathway at the cord or nerve root level will reduce both the amplitude and the latency of SEPs [4].

Although ideally a single observer should perform and score every neurological test, all observations in our study were carried out by one of three authors with each patient being tested to several clearly defined end points. Interobserver bias was further reduced by using four mechanical buzzers to independently deliver a $128-\mathrm{Hz}$ vibratory stimulus to joints both within (lower limbs) and outside (upper limbs) the field of block to accurately assess abnormalities of vibration sense. Unfortunately the physical size of the buzzer prevented testing of the big toe.

Romberg's test is a highly subjective and inaccurate test of dorsal column function abnormality. In our recently completed study using computerised dynamic posturography [5] only minor and clinically insignificant changes in stability scores were noted between an ambulating labour CSE analgesia group and a control group of nonlabouring mothers. Indeed three patients with abnormal Romberg signs were shown to have normal proprioceptive scores on dynamic posturography testing.

We disagree that proprioceptive fibres are more sensitive to a given dose of local anaesthetic than a similarly sized motor fibre. The actual response in vivo is less clear. Both fibres may actually be blocked at similar rates. This is because impulse transmission depends both on the axon diameter and the degree of myelination [6]. Since proprioceptive and somatic motor fibres are both of a similar diameter surrounded by similar amounts of myelin, approximately the same rate of local anaesthetic blockade would be expected. Therefore with a motor block of the lower limbs after regional blockade, one should also expect a reduction in proprioception. Our high-dose Caesarean section group demonstrating a high incidence of both motor block and dorsal column abnormality in the lower limbs, in sharp contrast to the low-dose labour epidural/CSE group, supports this theory.

Currently all that we can recommend is that if lower limb motor power is normal after ambulatory epidural/CSE analgesia, it is probably safe to allow mobilisation providing that the patient feels confident enough to do so.

\section{R. Fernando \\ M. G. Parry \\ Royal Free Hospital, \\ London NW3 2QG, UK}

\section{References}

1 Buggy D, Hughes N, Gardiner J. Posterior column sensory impairment during ambulatory epidural analgesia in labour. British Journal of Anaesthesia 1994; 73: 540-2.

2 Fernando R, Price CM. Posterior column sensory impairment during ambulatory epidural analgesia in labour. British Journal of Anaesthesia 1995; 74: 349-50.

3 Bell R, Parry MG, Fernando R, et al. Assessment of dorsal column function using somatosensory evoked potentials (SEPs) after ambulatory combined spinal epidural analgesia (CSE) for labour. International Journal of Obstetric Anesthesia 1997; 6: 199-200.

4 Beric A, Prevec TS. The early negative potential evoked by stimulation of the tibial nerve in man. Journal of Neurological Sciences 1981; 50: 299-306.

5 Pickering AE, Parry MG, Ousta B, Fernando R. Use of computerised dynamic posturography to assess maternal balance function after low dose combined spinal-epidural analgesia [abstract]. Anesthesiology 1998 (in press). 
6 Wildsmith JAW. Peripheral nerve and local anaesthetic drugs. British Journal of Anaesthesia 1986; 58: 692-700.

\section{Are you all right, Mrs Tilt?}

Resuscitation of the obstetric patient demands immediate manoeuvres to relieve aortocaval compression, i.e. uterine displacement either by the use of a wedge or lateral tilt of the bed or table [1]. Failure to perform such a manoeuvre at the outset of basic life support will make further resuscitative measures much less effective and is likely to affect outcome adversely [2]. We have observed during instructing basic obstetric life support that many candidates, while performing the task exactly to European Resuscitation Council guidelines, omit this vital manoeuvre during simulated resuscitation situations. These guidelines suggest, when faced with a collapsed patient, that responsiveness should be checked by shaking the patient and asking 'Are you all right?'. In an obstetric situation it is at this point that uterine displacement, either by use of a wedge or lateral tilt of the table, must be established.

It appears to us that candidates, obviously very well prepared in European Resuscitation Council guidelines, do not automatically change their mindset in the setting of an obstetric resuscitation. By replacing the 'Are you all right?' of the guidelines with 'Are you all right, Mrs Tilt?' (the 'Mrs Tilt' would obviously not be verbalised in real situations, it being in the mind of the rescuer as a prompt to tilt the patient) in obstetric resuscitation teaching, the mindset of the rescuer can be changed to 'obstetric' mode. This should lead to the rescuer carrying out this vital manoeuvre right at the start of obstetric resuscitation. Used in this way as an 'aide memoir', it may be a useful adjunct to obstetric resuscitation teaching.

\section{A. Dark \\ T. Engelhardt}

Aberdeen Royal Hospitals,

Aberdeen AB25 2ZN, UK

\section{References}

1 Lee RV, Rodgers BD, White LM, Harvey RC. Cardiopulmonary resuscitation of pregnant women.
American Journal of Medicine 1986; 81: 311-8.

2 Rees GAD, Willis BA. Resuscitation in late pregnancy. Anaesthesia 1988; 43: 347-9.

\section{Caudal epidurals: the 'whoosh test'}

Eastwood and colleagues (Anaesthesia 1998; 53: 305-7) state that they have demonstrated that the specificity of the 'whoosh test' is better than that of clinical impression. There are some points that I would like to make.

Firstly, I find the use of the terms 'sensitivity' and 'specificity' confusing in this context, where there is no obvious 'abnormal' or 'positive' result, but merely two different results. Indeed, I would have considered a result indicating an incorrectly sited needle to be a more intuitively 'positive' result rather than 'negative' as in the paper. Secondly, it is possible that the observed differences were due to chance and there is no real difference between the tests. Typically, McNemar's test would be used to look for correlation between observations of two binary variates. Moreover, in this case the availability of a 'good standard' allows a different approach. Considering only those 121 cases in which fluoroscopy demonstrated that the needle was correctly located, clinical impression identified 114 correctly and the 'whoosh test' identified 97 correctly. We can construct a contingency table thus

\begin{tabular}{lrc}
\hline & Correct & Incorrect \\
\hline Clinical impression & 114 & 7 \\
'Whoosh test' & 97 & 24 \\
& & \\
\hline
\end{tabular}

and use a Chi-squared test with one degree of freedom to give a $p$ value of 0.0011 , or of 0.0021 if Yates' continuity correction is used. The 'whoosh test' is significantly worse at identifying a correctly placed needle.

Now, considering instead the 10 cases in which fluoroscopy demonstrated that the needle was not correctly located, clinical impression identified only two correctly, but the 'whoosh test' identified six correctly. The numbers in this case are far too small too perform a Chisquared test, so an exact test is used to give a $p$ value of 0.170 and a mid $p$ value of 0.0948 . Neither of these two results approach significance, so Eastwood et al. have failed to demonstrate that the 'whoosh test' is significantly better at identifying an incorrectly placed needle.

Finally, the paper does not give all the information that the study provided. We know the results of the two tests individually, but not the results of the tests in combination. When actually performing a caudal injection a clinical impression of the position of the needle is obtained during insertion, whether or not we go on to perform a 'whoosh test'. These data could conveniently have been provided in the format shown at the foot of this page, which is essentially a ' $2 \times 2 \times 2$ ' table encapsulating all the available information.

What I suspect I would have found, had this information been provided, is that the best strategy is to only perform a 'whoosh test' if the clinical impression is that the needle is incorrectly placed. Of course it may be that the number of incorrectly sited needles is too small to prove this - perhaps a less skilled operator is needed to provide the data on this subgroup. The investigation does confirm the validity of the 'whoosh test', but the conclusions that may be drawn are not those of the original paper.

\section{A. M. J. Atherton}

Fazakerley Hospital,

Liverpool L9 7AL, UK

\begin{tabular}{lllll}
\hline & \multicolumn{3}{c}{ Fluoroscopy } \\
\cline { 2 - 5 } & \multicolumn{2}{c}{$\begin{array}{c}\text { Correct } \\
\text { Clinical impression }\end{array}$} & $\begin{array}{c}\text { Incorrect } \\
\text { Clinical impression }\end{array}$ \\
& Correct & Incorrect & Correct & Incorrect \\
'Whoosh test' & $\mathrm{n}_{1}$ & $\mathrm{n}_{2}$ & $\mathrm{n}_{3}$ & $\mathrm{n}_{4}$ \\
Incorrect & $\mathrm{n}_{5}$ & $\mathrm{n}_{6}$ & $\mathrm{n}_{7}$ & $\mathrm{n}_{8}$ \\
& & & & \\
\hline
\end{tabular}




\section{A reply}

Dr Atherton criticises the use of the diagnostic test statistics of sensitivity and specificity in our prospective evaluation of the whoosh test. I do not agree with his criticisms and I would like to provide further statistical evidence.

Fluoroscopic imaging provides a gold standard against which to measure other tests for caudal epidural needle placement; statistically, the treatment of needle placement status is no different to that of 'disease' status more commonly associated with diagnostic tests. Here is a fuller analysis of the diagnostic test results concerned:

For the study as a whole: prevalence (pre-test likelihood of correct needle placement) $=92 \%$.

For clinical impression: + ve predictive (post-test likelihood of incorrect needle placement) $=93 \%$; - ve predictive value A (post-test likelihood of correct needle placement) $=78 \%$; - ve predictive value $\mathrm{B}$ (post-test likelihood of correct needle placement despite - ve test) $=22 \%$ sensitivity (true positive rate) $=94 \%$; specificity (true negative rate) $=20 \%$; likelihood ratio (and 95\% confidence interval) for + ve test $=1.18$ (0.98-1.92); likelihood ratio (and 95\% confidence interval) for - ve test $=0.29$ (0.08-1.18).

For whoosh test: + ve predictive (post-test likelihood of incorrect needle placement $)=96 \%$; - ve predictive value A (post-test likelihood of correct needle placement $)=80 \%$; - ve predictive value $\mathrm{B}$ (post-test likelihood of correct needle placement despite - ve test) $=20 \%$ sensitivity (true positive rate) $=80 \%$; specificity (true negative rate) $=60 \%$; likelihood ratio (and 95\% confidence interval) for + ve test $=2.00(1.15$ to 4.78); likelihood ratio (and 95\% confidence interval) for - vs test $=0.33(0.19$ to 0.68 )

It is perhaps more meaningful, in a clinical sense, to think in terms of odds in this situation. The post-test odds of correct needle placement equals the pretest odds of correct needle placement multiplied by the likelihood ratio. You can consider the likelihood ratio as indicating the value of the test for increasing certainty about correct needle placement. The likelihood ratios for whoosh test suggest its superiority (in statistical terms) to the clinical impression. The confidence intervals for the likelihood ratios for clinical impression include unity and therefore one cannot make robust inference from them; ideally larger numbers would be sought. The greater variation here is explained by the greater subjectivity of clinical impression compared with the whoosh test.

Analysis of the value of the whoosh test when indicated by clinical impression compared with routine use of the whoosh test would, as Dr Atherton suggests, be useful. This was not part of the current study design and therefore it would not have been appropriate to perform a retrospective subgroup analysis. Any future larger study of the whoosh test should aim to eliminate as much bias and confounding as possible in the study design if the real effect of whoosh test directed by clinical impression is to be resolved. For example, the intention to use a whoosh test could bias the clinical impression; therefore randomisation to whoosh, no whoosh or clinically indicated whoosh should happen after the clinical impression is recorded.

Dr Atherton suggests working on a null hypothesis of no association between test and fluoroscopy results either in discrete paired comparisons of binomial proportions or in a stratified analysis of the contingency tables. One would hope that the ethics committee would not have allowed the study to proceed had the answer to this test of hypothesis not been determined in advance. The most challenging part of the diagnostic test evaluation is to weigh the clinical consequences of a false positive result against those of a false negative result. To consider these elements in separate statistical analyses with independent probabilities would be specious. The diagnostic test approach facilitates clinical interpretation and maintains statistical robustness.

\section{E. Buchan}

Centre for Clinical Informatics, Institute of Public Health, University of Cambridge, CB2 2SR, UK

\section{latrogenic puncture of the laryngeal mask airway cuff}

A 30-year-old male, intravenous drug user presented for drainge of a forearm abscess. Due to problems with veins anaesthesia was induced with sevoflurane in oxygen; a size 4 laryngeal mask airway (LMA) was easily inserted. The cuff was inflated with $25 \mathrm{ml}$ of air and correct placement confirmed. Peripheral venous access was initially unsuccessful and cannulation of the left internal jugular vein was attempted using an $18 \mathrm{G}$ abbocath cannula with a 10-ml syringe attached; the right internal jugular vein was sclerosed. Advancing the cannula, $5 \mathrm{ml}$ of air under pressure entered the syringe unexpectedly and the cannula was withdrawn. The patient was breathing spontaneously and there was no suggestion or evidence of a tension pneumothorax. It was obvious the LMA cuff had been punctured and a further $10 \mathrm{ml}$ of air was introduced into the cuff. Despite the puncture of the LMA cuff, the pilot balloon remained inflated and no obvious air leak was present. The capnograph trace and reservoir bag movements remained unchanged, with normal breath sounds heard on auscultation of the lungs and side of the neck. The pressure in the cuff was measured through the pilot balloon and found to be $22 \mathrm{cmH}_{2} \mathrm{O}$. Throughout the 25-min procedure no signs of cuff deflation appeared. The pressure in the cuff remained at $22 \mathrm{cmH}_{2} \mathrm{O}$. Intravenous access in a dorsal foot vein was established and anaesthesia maintained with isoflurane in a $\mathrm{N}_{2} \mathrm{O} / \mathrm{O}_{2}$ mixture. The remaining procedure was uneventful.

Examination of the LMA cuff in a beaker of water and inflated with $45 \mathrm{ml}$ of air resulted in a stream of bubbles from the puncture site (figure top of next page). Whatever volume of air was introduced, the leak always stopped with a residual volume of $24 \mathrm{ml}$ in the cuff and a cuff pressure of $22 \mathrm{cmH}_{2} \mathrm{O}$. Interestingly, the deflation test with the mask cuff to a high vacuum did not result in gradual re-inflation as might be expected.

The silicone cuff of the LMA is permeable to a variety of gases, with 


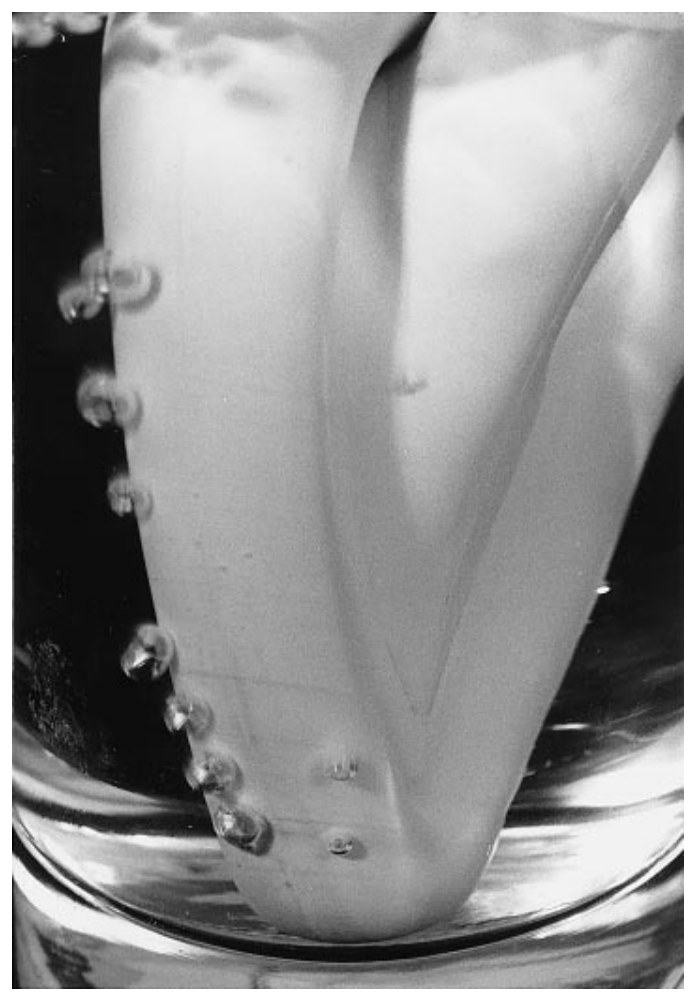

$\mathrm{CO}_{2}$ and $\mathrm{N}_{2} \mathrm{O}$ rapidly diffusing through the membrane [1], causing a rise in pressure within the air-filled cuff [2]. The diffusion of gas into the LMA cuff may have compensated for any leak, but more likely, as gas diffused into the cuff and the pressure increased, the hole in the silicone rubber opened, acting as a pressure limiting leak at $22 \mathrm{cmH}_{2} \mathrm{O}$. Dental damage to the LMA cuff has been reported [3, 4]. In the first report the LMA was used in a 'can't intubate, can't ventilate' scenario and a $0.5-\mathrm{cm}$ tear noted. The second report during elective use described the replacement of the LMA on three occasions due to a leak. We are not aware of any reports of iatrogenic puncture of the LMA cuff and its subsequent use.

Three points arise from this incident. First, neck vein cannulation may be difficult due to distortion of the oropharynx by the LMA. Second, the importance of performing all pre-use tests is highlighted [5]. In this case the puncture of the LMA was obvious, but if the device had been sterilised for re-use, the leak would have been detected by the inflation test only $(50 \%$ overinflation with the device under water). Finally, inadvertent puncture of the LMA cuff may not result in complete cuff deflation and the device may continue to function normally.

\section{A. Patel \\ A. Pearce \\ Guy's Hospital, \\ London SE1 9RT, UK}

\section{References}

1 Lumb AB, Wrigley MW. The effect of nitrous oxide on laryngeal mask cuff pressure. In vitro and in vivo studies. Anaesthesia 1992; 47: 320-3.

2 Brimacombe J, Berry A. Laryngeal mask cuff pressure and position during anaesthesia lasting 1-2 hours. Canadian Journal of Anaesthesia 1994; 41: 589-93.

3 Pennant JH, Gajraj NM, Griffith K. Puncture of the laryngeal mask airway cuff. Anaesthesia 1994; 49: 448.

4 McLure HA. Dental damage to the laryngeal mask. Anaesthesia 1996; 51: 1078-9.

5 Brimacombe JR, Brain AIJ. The Laryngeal Mask Airway: A Review and Practical Guide. London: W. B. Saunders Company Ltd, 1997.

\section{The intubating laryngeal mask airway (ILMA) in failed and difficult intubation}

We were interested to read about the three cases of difficult intubation overcome by the use of the ILMA (Anaesthesia 1998; 53: 343-8). We have similarly noted success rates comparable to those of the original investigators $[1,2]$ in a series of 100 patients with normal airways. However, we wish to report one case in which tracheal intubation via the ILMA proved unsuccessful.

A 58-year-old Chinese man with myasthenia gravis was admitted to the intensive care unit because of ventilatory failure 2 days after an emergency appendicectomy. At the time of surgery, trachael intubation had proved impossible following rapid sequence induction and was eventually achieved using a fibreoptic bronchoscope, after the patient had safely been woken up. Postoperatively, he had been sent to the high dependency unit. On admission to ICU, he was responsive to commands and was able to maintain an oxygen saturation of $98 \%$, but breathing was laboured with shallow tidal volumes, it was possible to manually assist ventilation using a facemask. Following propofol $20 \mathrm{mg}$, direct laryngoscopy revealed a grade 4 view [3]. Tracheal intubation was attempted, using a gum elastic bougie and stylet, by three specialist anaesthetists, with no success. Initial use of the fibreoptic bronchoscope also proved unsuccessful. A size 4 ILMA was then inserted and adequate ventilation achieved. However, it proved impossible to pass a size $7.0 \mathrm{~mm}$ silicon tracheal tube via the ILMA. A fibreoptic bronchoscope was passed down the metal stem of the ILMA, but the view was obscured because of bleeding. The ILMA was removed and after further tries the trachea was eventually intubated using a size $7.0 \mathrm{~mm}$ tracheal tube railroaded over a fibreoptic bronchoscope passed nasally.

It is important to report both success and failure especially since the ILMA is a new device which has been developed based on MRI studies in one particular population. In addition, all three cases described by Parr et al. had 
received neuromuscular blockers to aid intubation.

\author{
C. L. Lim \\ L. Hawthorne \\ P. C. Ip-Yam \\ Singapore General Hospital \\ Singapore
}

\section{References}

1 Kapila A, Addy EV, Verghese C, Brain AIJ. The intubating laryngeal mask airway: an initial assessment of performance. British Journal of Anaesthesia 1997; 79: 710-3.

2 Brain AIJ, Verghese C, Addy EV, Kapila A, Brimacombe J. The intubating laryngeal mask. II: a preliminary clinical report of a new means of intubating the trachea. British Journal of Anaesthesia 1997; 79: 704-9.

3 Cormack RS, Lehane J. Difficult intubation in obstetrics. Anaesthesia 1984; 39: 1105-11.

\section{Ethics and research in anaesthesia}

In his recent editorial on Ethics and Research in Anaesthesia (Anaesthesia 1998; 53: 422-3), Dr Sneyd made an error which I wish to correct. In the section on Financial interests, he indicated that the British Journal of Anaesthesia does not require authors to make any disclosure of relevant financial interests. However, in the Guide to Contributors, published in every issue of British Journal of Anaesthesia, there is a statement which has appeared since March 1996: 'there should be a clear declaration of any financial or commercial interest which any author may have in the material'.

The British Journal of Anaesthesia has held a long-standing interest in promoting high ethical standards in anaesthetic research. We drafted the editorial published in the four leading anaesthetic journals on duplicate publication [1] and collaborate in order to try to reduce the extent of this problem. During my time as Editor of the British Journal of Anaesthesia from 1987 to 1997, I refrained from publishing some material passed by local ethics committees, on the grounds that it did not meet our higher own ethical standards. More recently, the
$B J A$ was invited to join a committee on publication ethics, convened by Dr Richard Smith, Editor of the British Medical Journal.

Detection of fraud by the Editor of a Journal is particularly difficult. This problem can only be obviated by close local institutional monitoring of research; however, the Guide to Contributors in the $B J A$ also indicates that the Editor might wish to inspect all raw data if any suspicion of fraud arises.

Obviously, there are many aspects of Dr Sneyd's editorial on which I could comment at length. However, I would merely make a plea that all authors, either novice or seasoned, read the guide to Contributors for a specific journal before submitting a manuscript to that journal; clearly it would be unreasonable not to anticipate that these guidelines are updated at regular intervals.

\section{G. Smith \\ Leicester Royal Infirmary, \\ Leicester LE1 5WW, UK}

\section{Reference}

1 Smith G, Miller R, Saidman LJ, Morgan M. Ethics in Publishing. British Journal of Anaesthesia 1991; 66: 421-422.

A reply

Professor Smith has correctly pointed out an error in my editorial. I apologise for this inaccuracy.

\section{J. R. Sneyd \\ Derriford Hospital \\ Plymouth PL6 8DH}

\section{Acute arrhythmias on induction of anaesthesia in a child with a blocked shunt}

A 13-year-old child with Dandy-Walker syndrome and a ventriculo-atrial shunt presented with a history of occipital headache, associated with nausea and vomiting, but normal conscious level. A CT scan showed dilated ventricles and a cyst consistent with the DandyWalker malformation. This contained a poorly functioning ventricular catheter and shunt revision was indicated. The anaesthetist detected a pan-systolic murmur and ordered an ECG, which showed sinus rhythm at 64 beats.min ${ }^{-1}$ with inverted $\mathrm{T}$ waves in leads III, aVR, aVF, V1, V2 and V3. In the absence of a previous cardiac history, it was decided to proceed. A modified rapid sequence induction was performed, with fentanyl, thiopentone and suxamethonium, followed by vecuronium. A bradycardia on intubation resolved, but $5 \mathrm{~min}$ later a supraventricular tachycardia at 160 beats.min ${ }^{-1}$ developed, with a blood pressure of $190 / 110 \mathrm{mmHg}$ and oxygen saturation of $90 \%$ whilst receiving 100\% oxygen. The child developed frank pulmonary oedema. The neurosurgeon aspirated $20 \mathrm{ml}$ of cerebrospinal fluid from the Holter valve and the arrhythmia ceased. Blood pressure settled and oxygen saturation improved. The patient's lungs were ventilated on the intensive care unit after insertion of an external ventricular drain and the trachea extubated $24 \mathrm{~h}$ later. The ECG changes reverted and the murmur disappeared. Echocardiography confirmed a normal heart. General anaesthesia for insertion of a definitive ventriculoperitoneal shunt was subsequently uneventful.

Ventriculo-atrial shunts are associated with pulmonary thrombo-embolism and pulmonary hypertension, but preoperative findings were not suggestive of this [1]. Suxamethonium increases intracranial pressure, but the vomiting child poses an anaesthetic dilemma. Modified rapid sequence induction was appropriate but may have precipitated the arrhythmia. Fentanyl and thiopentone did not offset the effects of suxamethonium and the hypertensive response to intubation. The conscious level of the child was a poor indication of his critically raised intracranial pressure, but the murmur and ECG changes were significant. Pulmonary oedema has been described after induction of anaesthesia for revision of a blocked ventriculoperitoneal shunt [2]. The termination of a supraventricular tachycardia on induction of anaesthesia, by emergency aspiration of CSF from the Holter valve has not previously been described.
E. M. C. Ashley
St Peter's Hospital,
Chertsey, Surrey KT16 OPZ, UK 


\section{J. O'Riordan}

St Georges Hospital,

London SW17 0QT,

UK

\section{References}

1 Butler PJ, Wheeler RA, Spargo PM. Life-threatening complications during anaesthesia in a patient with a ventriculo-atrial shunt and pulmonary hypertension. Anaesthesia 1990; 45: 946-8.

2 Braude N, Ludgrove T. Neurogenic pulmonary oedema precipitated by induction of anaesthesia. British Journal of Anaesthesia 1989; 62: 101-3.

\section{Ventilation during percutaneous tracheostomy}

Percutaneous tracheostomy is a technique that has revolutionised airway management in the intensive care setting. One of the potential problems with the technique is damage to the tracheal tube or cuff thereof with the introducer needle of the percutaneous tracheostomy set. To prevent this complication, the laryngeal mask airway (LMA) has been used to provide a means of ventilation while the procedure is performed [1]. However, this technique is not without risk and the requirement to re-intubate the trachea with a cuffed tube may occur at any stage, necessitating removal of the LMA, laryngoscopy and subsequent intubation.

The recently introduced intubating laryngeal mask (ILM) may provide a useful alternative technique, enabling ventilation of the lungs and the ability to perform rapid re-intubation should the need arise. Preliminary results would indicate a $99 \%$ success rate for blind trachael intubation using the ILM [2] and its successful use in cases of difficult intubation has recently been described [3]. The use of the LMA is, however, contraindicated in cases with decreased gastric motility and increased pulmonary compliance. We have used the ILM as a ventilatory aid during percutaneous tracheostomy in a number of patients in whom use of LMA was not contraindicated and have found it to be an effective technique, freeing the trachea of the presence of a tracheal tube while retaining the ability to quickly re-secure the airway should the need arise.

\section{A. Jones \\ A. J. Ball}

Dorset County Hospital, Dorchester DT1 2JY, UK

\section{References}

1 Lyons BJ, Flynn CGM. The laryngeal mask simplifies airway management during percutaneous dilational tracheostomy. Acta Anaesthesiology Scandanavica 1995; 39: 414-5.

2 Brain AIJ, Verghese C, Addy EV, Kapila A, Brimacombe J. The intubating laryngeal mask. II A preliminary clinical report of a new means of intubating the trachea. British Journal of Anaesthesia 1997; 79: 704-9.

3 Parr MJA, Gregory M, Baskett PJF. The intubating laryngeal mask. Use in failed and difficult intubation. Anaesthesia 1998; 53: 343-8.

\section{Percutaneous dilatational tracheostomy in children}

The case report on complications of percutaneous dilatational tracheostomy (PDT) in children (Anaesthesia 1998; 53: 477-80) emphasizes the risks of extending an invasive technique beyond the original target population, but does not present conclusive evidence that the reported complications were solely attributable to the technique, were obligatorily inherent in the technique or occurred with greater frequency and to a greater degree in children. Without the total numbers or outcomes for different ages of children for tracheostomy via a formal or percutaneous approach, or indeed prolonged intubation, it is impossible to qualify the cases reported, and therefore the recommendations, in any risk analysis.

Tracheal stenosis is of multifactorial origin, circumferential ischaemia being a principal cause in the intubated patient and the extent of local trauma being one determinant with an invasive procedure. The smaller more mobile structure in children, with less rigid cartilage, could engender such trauma in PDT by a lower 'first-pass' success rate, a higher incidence of posterior wall injury and the likelihood of invaginated splintered cartilage if the dilatation takes place through, as opposed to between, the rings. Whilst these factors may potentiate stenosis in children, there is clearly an operator-determined element in the extent to which they occur, particularly with a new technique, this consideration being implicitly acknowledged by the authors' reference to the complications of a formal surgical tracheostomy being negligible in 'skilled' hands.

On the basis of medical and lay concern over such hazards of new procedures, SERNIP [1] was established as the statutory body 'policing' these developments, making it worthy of comment when a technique not registered for adult use is introduced into paediatric practice outwith a formal trial or observational study. This aspect and subsequent doubt as to the quality of informed consent obtained in this scenario appear to be of greater significance than the two reported complications.

Formal appraisal is warranted, but a true comparison between the outcomes from skilled exponents of both approaches is intrinsically difficult because of a lack of paediatric experience with the percutaneous technique and its usual practice by nonsurgical personnel. Given that it would be hard to justify complications occurring during a 'learning-curve' in this vulnerable population, it is difficult to anticipate ethical approval for such a study, or SERNIP ratification for more widespread adoption even with favourable results.

As such it is unclear how this issue can progress, but it would appear in the interim that, in view of the above considerations, complications of any nature after a percutaneous approach in children may well prove difficult to defend.

\section{D. D. Bell}

The General Infirmary at Leeds Leeds LS1 3EX,

$$
\text { UK }
$$

\section{Reference}

1 Safety and Efficacy Register of New Interventional Procedures of The Medical Royal Colleges (SERNIP). 
Dangers of using a pneumatic pressure bag to increase transfusion rate

I was interested to read the letter by Kinnear and Stase (Anaesthesia 1998; 53: 408) relating a case of extravasation of fluid from a pressurised peripheral line in a patient following cardiopulmonary bypass (CPB). The leak occurred through an upstream hole in the vein due to a previous attempt at siting the cannula in the same arm. I have had a similar, though potentially more serious, experience.

A large-bore cannula was sited in a vein in the patient's left forearm together with a radial artery cannula prior to commencement of anaesthesia for CPB. Anaesthesia progressed uneventfully until after separation from CPB, when, whilst the patient was hypovolaemic, a rapid transfusion of fluid was commenced via the peripheral line with the aid of a pneumatic pressure bag device. Following transfusion of $500 \mathrm{ml}$ of gelofusine and a unit of autologous blood, the patient's arterial pressure, as measured via the radial artery cannula, started to fall rapidly, the central venous pressure remaining low. Palpation of the aorta suggested that the blood pressure was significantly higher than that displayed via the radial line. This was confirmed by direct aortic pressure measurement, a discrepancy of $>60 \mathrm{mmHg}$ being found. The peripheral line was abandoned as a route of fluid administration at this point and anaesthesia progressed uneventfully. On removal of the surgical drapes the left forearm was observed to be very swollen and tense. Luckily the swelling of the affected limb abated over the ensuing $48 \mathrm{~h}$ with elevation alone. I concluded that the peripheral line had 'tissued' and a large proportion of the transfusion had extravasated under pressure leading to a 'compartment syndrome' externally compressing the radial artery and so artefactually decreasing the systolic blood pressure displayed on the monitor.

The patient's arms were secured by using a drawsheet folded over the arm and tucked in, as in Kinnear and Scase's case; however, no previous attempt at venous cannulation had occurred in this patient's arm. I can only surmise that the use of the pneumatic pressure bag had resulted in the bursting of the peripheral vein, perhaps contributed to by the drawsheet compressing the vein proximally, leading to extravasation of fluid at high pressure with the resultant compression of the radial artery.

I suggest that pneumatic pressure bags should not be used to increase the rate of transfusion into any peripheral line that cannot be observed easily by the anaesthetist. I would also suggest that when a folded drawsheet is used to secure the arms of a pateint prior to cardiopulmonary bypass, sufficient slack is left to allow for the inevitable swelling that may occur following $\mathrm{CPB}$ due to an increase in extracellular fluid.

\section{N. Hunter \\ St Thomas' Hospital, \\ London SE1 7EH, UK}

\section{Pain and venous cannulation}

In Dr Brown's paper regarding pain from cannula insertion (Anaesthesia 1998; 53: 495-6), the results show no statistical difference between pain from cannulation with a $20 \mathrm{G}$ versus a $22 \mathrm{G}$ Venflon in healthy volunteers. The hand used first and which hand received which size of cannula did not influence these results. I wondered whether there was any influence on the results by the order in which the cannulae were inserted. Pain pathways are complex, subject to modulation from many sources and existing in a plastic, adaptable system [1]; the stimulation arising from the first cannulation must surely influence the perceived stimulus of the second. One might expect that 'the first cut is the deepest'.

\section{J. Nanson \\ North Hampshire Hospital, Basingstoke RG24 9NA, UK}

\section{Reference}

1 Coniam SW, Diamond AW. Practical Pain Management, 1st edn. Oxford University Press.

\section{Accuracy of bedside haemoglobin measurement}

The Hemocue is a popular device for measuring haemoglobin at the point of care and its accuracy must be established. It was therefore comforting to read that Lardi and colleagues (Anaesthesia 1998; 53: $349-52$ ) were able to confirm our results in their evaluation of the Hemocue using arterial blood samples [1]. However, I would like to alert users to the poor repeatability of haemoglobin estimates from capillary blood samples. In our evaluation of the Hemocue, we found a high variability between the estimates from sequential capillary samples. As a result, we noted a significant difference between the variance of the Coulter JT measurements and Hemocue estimates using capillary samples, but not for venous and arterial samples. As capillary sampling is commonly used at the point of care especially by nonmedical staff, Hemocue's haemoglobin estimates from these samples must be interpreted with caution.

P. P. Chen

Alice Ho Miu Ling Nethersole

Hospital,

China

\section{Reference}

1 Chen PP, Short TG, Leung DHY, Oh

TE. A clinical evaluation of the

Hemocue haemoglobinometer using capillary, venous and arterial samples. Anaesthesia and Intensive Care 1992; 20: 497-500.

\section{The influence of smoking on postoperative nausea and vomiting}

In response to a letter from Dr Dolenska (Anaesthesia 1997; 52: 1021), Koivuranta et al. (Anaesthesia 1998; 53: 413) defend the findings of their survey [1] that postoperative nausea and vomiting (PONV) is less common in both male and female smokers compared with nonsmokers. We have made some similar observations in recent unpublished work investigating PONV in day-case arthroscopy patients.

Our patients underwent a standardised anaesthetic and were exposed to either isoflurane or desflurane. We found a significant incidence of nausea in the desflurane group. Analysis of these 76 patients, utilising a Chi-squared test, 
showed nonsmokers to be at a significantly higher risk of nausea than smoking patients (Table 1). Further statistical analysis of our results was performed with a Chi-squared test, with Yates' correction for continuity, for the smaller single sex samples (54 male and 22 female patients). There appeared to be statistical significance for the group as a whole and male patients $(\mathrm{p}<0.05)$. However, for female patients, the association of smoking protecting against nausea was not significant $(\mathrm{p}<0.1)$. This may be due to both sample size and a female predisposition to PONV.

There is other support for the observation that smoking protects from PONV [2]. Koivuranta et al. speculate that smokers are more tolerant to anaesthetic gases and other toxins than nonsmokers and consequently have a lower incidence of PONV. We think it is unlikely that any action of inhaled nicotine should protect from PONV, but postulate that one of the many other complex component chemicals within cigarette smoke may have an anti-emetic effect. Further research should clarify the effect of smoking on PONV in all categories of patient. The prospect of identifying the anti-emetic mechanism of smoking may have exciting implications for our understanding and future treatment of postoperative nausea and vomiting.

Table 1 The incidence of nausea in smokers versus nonsmokers exposed to desflurane.

\begin{tabular}{llcc}
\hline & Sex & Smokers & Nonsmokers \\
\hline \multirow{2}{*}{ Nauseated } & Female & 1 & 7 \\
& Male & 0 & 6 \\
Nausea-free & Female & 5 & 9 \\
& Male & 17 & 31 \\
& & & \\
\hline
\end{tabular}

M. Hough

B. Sweeney

Poole General Hospital,

Poole, Dorset, UK

\section{References}

1 Koivuranta M, Laara E, Snare L, Alahuhta S. A survey of postoperative nausea and vomiting. Anaesthesia 1997; 52: 443-9.

2 Cohen MM, Duncan PG, DeBoer DP, Tweed WA. The postoperative interview: assessing risk factors for nausea and vomiting. Anesthesia and Analgesia 1994; 78: 7-16.

\section{The Budget: bad news for} British anaesthetists in the USA

We are among the small number of British anaesthetists who have elected to spend time as visiting faculty at institutions in the USA.

Until recently our US earnings had been protected from US tax by virtue of a tax treaty and from UK tax by virtue of the co-called foreign earnings deduction. The latter allowed a 100\% deduction for earnings from employment carried out wholly or partly abroad during a 'qualifying period' of 365 days or more. For many years this tax break has allowed US institutions to offer visiting British doctors a salary equivalent to the net income of junior American colleagues. Salaries are just high enough to attract British doctors and yet low enough to make visiting faculty programmes economically viable. The considerable relocation and start-up costs mean that most of us only 'break even' at the end of 12 months.

In his recent Budget statement, the Chancellor of the Exchequer announced the cessation of the foreign earnings deduction. The principal targets of this legislation appear to be a small number of high earning individuals who have exploited the system to avoid paying tax on a significant portion of their income [1]. Doctors in our position now face a large tax bill upon our return to the UK - a bill that we have neither expected nor made provision for. Those currently planning to travel to the USA face financial uncertainty. If US salaries have to be increased to offset this new tax liability the door to future exchanges will effectively be closed and a truly unique and valuable educational resource will be lost, perhaps for ever. Inevitably a small number of doctors will choose to remain in the USA. Our belief is that, either way, the National Health Service is the loser.

We ask both the Chancellor and the Secretary of State for Health to examine urgently the far reaching implications of this budgetary measure before the damage is irreparable. We suggest that British doctors planning to work in the USA contact their host institution and their tax office.

\section{J. E. Arrowsmith}

Duke University Medical Center, Durham NC 27710, USA.

\section{E. Nicol}

University of Michigan Medical

Center,

Ann Arbor, MI 48105, USA.

\section{R. C. Bacon}

University of Washington Medical

Center,

Seattle, WA 98195, USA.

\section{Reference}

1 Budget Office Press Release (IR33). 17 March 1998. 